\title{
Duodenal Obstruction
}

National Cancer Institute

\section{Source}

National Cancer Institute. Duodenal Obstruction. NCI Thesaurus. Code C79548.

Blockage of the normal flow of stomach contents through the duodenum. 